\title{
Correction to: In stability and Stasis Among the Microbiome of Seagrass Leaves, Roots and Rhizomes, and Nearby Sediments Within a Natural pH Gradient
}

\author{
Raymond B. Banister ${ }^{1,2} \mathbb{D} \cdot$ Melbert T. Schwarz $^{1} \cdot$ Maoz Fine $^{3,4} \mathbb{D} \cdot$ Kim B. Ritchie $^{5} \cdot$ Erinn M. Muller $^{1}$ D \\ (c) Springer Science+Business Media, LLC, part of Springer Nature 2021
}

Correction to: Microbial Ecology

https://doi.org/10.1007/s00248-021-01867-9

Due to typesetting mistake, the affiliation ids were not changed in sequential order which resulted to mismatch of the authors institutions.

The original version has been corrected.

The original article can be found online at https://doi.org/10.1007/ s00248-021-01867-9.

Raymond B. Banister

rbanister2019@my.fit.edu

1 Mote Marine Laboratory, Coral Health and Disease

Program, Sarasota, FL, USA

2 Institute for Global Ecology, Florida Institute of Technology, 150, W University Blvd, Melbourne, FL 32901, USA

3 The Goodman Faculty of Life Sciences, Bar-Ilan University, 52900 Ramat Gan, Israel

4 The Interuniversity Institute for Marine Science, P.O.B. 469, 88103 Eilat, Israel

5 Department of Natural Sciences, University of South Carolina Beaufort, 801, Carteret St., Beaufort, SC 29906, USA 